\title{
Attitude towards Food Associated with Food Preferences in Japanese Elementary and Junior High School Students
}

\author{
Tomoko Osera ${ }^{1,2}$, Mitsuyo Awai ${ }^{3} \&$ Nobutaka Kurihara ${ }^{2}$ \\ ${ }^{1}$ Department of Nutrition and Health Sciences, Faculty of Food and Nutritional Sciences, Toyo University, \\ Gunma, Japan \\ ${ }^{2}$ Hygiene and Preventive Medicine, Graduate School of Home Economics, Kobe Women's University, Hyogo, \\ Japan \\ ${ }^{3}$ School of Nursing, Kansai University of Nursing and Health Science, Hyogo, Japan \\ Correspondence: Nobutaka Kurihara, MD; PhD. Hygiene and Preventive Medicine, Graduate School of Life \\ Science, Kobe Women's University; 2-1 Higashisuma-Aoyama, Suma, Kobe, Japan. Tel: 81-787-372-417. \\ E-mail: kurihara@suma.kobe-wu.ac.jp
}

Received: September 6, 2020

Accepted: October 21, $2020 \quad$ Online Published: November 6, 2020

doi:10.5539/jfr.v9n6p42

URL: https://doi.org/10.5539/jfr.v9n6p42

\begin{abstract}
Food-related preferences and practices are formed in early childhood. Our prior study suggested that children's food preferences were related to their attitude towards food, especially "concern about food" and "respect for food." In this study, we investigated the association of the high and low level of "attitude towards food" to food preferences of 6-16-year-old students. In 2017, a questionnaire was given to 1,658 students and guardians who attended public school and junior high school in the Hyogo prefecture of Japan. A total of 497 (29.9\%) completed questionnaires were returned. The Kruskal-Wallis, Mann-Whitney U, and Jonckheere-Terpstra tests were employed to assess any associations between the independent variables and three levels of "concern about food" and "respect for food" with significance being at $p<0.05$. The number of foods disliked by the students significantly decreased with increasing levels of "attitude towards food". The present study suggests that the students" "attitude towards food" was associated with their food preferences.
\end{abstract}

Keywords: food preference, attitude towards food, elementary school children, junior high school students

\section{Introduction}

Food preferences are very complicated. Taste preferences are created in early childhood when children are predisposed to prefer high-energy, sugary, and salty foods, and also tend to reject new foods (Schwartz et al., 2011; Cosmi, Scaglioni \& Agostoni, 2017). As noted above, these appear to be intimately related to children's behavior and development. Food neophobia is generally regarded as the reluctance to eat, or the avoidance of new foods. In contrast, picky or fussy eaters are usually defined as children who consume an inadequate variety of foods through rejection of foods that are familiar, as well as unfamiliar, to them (Dovey, Staples, Gibson \& Halford, 2008). Picky eating among children is a common concern, yet little is known about how these behaviors develop in early childhood. Picky eaters consume fewer total fats, less energy, and less protein than children without picky eating behaviors (Dubois, Farmer, Girard \& Peterson, 2007). Picky eating can affect children's nutritional intake and dietary quality, and negatively impact their growth and development (Dubois et al., 2007; Cano et al., 2016). It is important to improve children's food neophobia and/or picky or fussy eating habits. In this study, all of these behaviors are defined as food preferences, as teachers and parents were unable to distinguish among these behaviors. Eating habits learned in early childhood often continue throughout adulthood (Ventura \& Worobey, 2013). Some researchers found that limited food preferences relate to children's human environment, with preferences resembling those of their mother, father, and siblings (Birch, 2013; Pliner \& Pelchat, 1986). Parental food habits and feeding strategies are the most important determinants of a child's eating behavior and food choices (Scaglioni et al., 2018). A preference for fat taste in mothers correlates with overweight and obesity in their children (Sobek et al., 2020). Parents of picky eaters were more likely to report that their children consumed a limited variety of food (Mascola, Bryson \& Agras, 2010; Osera, Tsutie, Kobayashi \& Kurihara, 2016). It is important to increase a child's eating experience. Cosmi suggested that while genetically determined individual differences exist, repeated offerings of food can modify innate preferences 
(Cosmi, Scaglioni \& Agostoni, 2017). Early-life experiences with various tastes and flavors have a role in promoting future healthy eating (Scaglioni et al., 2018).So, the role of parents for children during childhood is important.

While the role of parents in the development of their children's food preferences is important, the specific method is not known. Our previous study suggested that 3-5-year-old children's "concern about food" and "respect for food" were associated with a decrease in the number of foods they disliked (Osera, Tsutie, Kobayashi \& Kurihara, 2016). These concepts are reported in Japan to be important in the development of mind and body during childhood in "shokuiku" (a type of nutritional education) during kindergarten (MEXT, 2018). "Concern about food" and "Respect for food" are classified as attitude. In the KAB model, attitude is regarded as a leading factor of behavior.

In addition "Respect for food" important for not only food preferences but also Sustainable Development Goals (SDGs), there are connected with good health and well-being and quality education (United Nations, 2015). Our previous study suggested that the relationship between food preferences and their attitude especially "Respect for food" during childhood (Osera, Tsutie, Kobayashi \& Kurihara, 2014). In the present study, we aimed to determine whether the same concepts could be found in children of 6-16 years of age in elementary and junior high school.

\section{Method}

This was a cross-sectional study. From May to September 2017, a questionnaire was given to 1,658 mothers and their children, 6-16 years of age, who lived in Hyogo prefecture. In addition, we suggested that the 6-9 year old students answer the questionnaire with their guardians.

\subsection{Questionnaire}

Anthropometric measurements (weight and height) were self-reported. Body mass index (BMI) was used to indirectly assess adiposity and was calculated as weight $/$ height ${ }^{2}\left(\mathrm{~kg} / \mathrm{m}^{2}\right)$. BMI cutoffs for the children were generated from pooled international data for BMI and were linked to BMI cutoff points used in adults (Kazmarzyk, Janssen, Morrison \& Tremblay, 2007). The Japan Obesity Society's BMI cutoff points for adults were used in the current analyses to classify weight status in Table 1 (Miyazaki, 2018).

Student's food habits and lifestyle, including behaviors and attitudes, are shown in Tables 2 and 3. The questionnaire contained nine questions on food habits and attitudes toward food which referred to our previous study's questionnaire (Osera, Taniguchi, Hashimoto \& Kurihara, 2018; Osera et al., 2017a). The questionnaire comprised one questionnaire on "concern about food", "respect for food", self-rated health (SRH), "talk about food", "talk about taste", "help set the table", "help cooking", "liking school lunch", "liking home meals". Both 5 point rating scales were used, with higher scores indicating more positive food habits. For example, questions regarding 'concern about food' utilized a 5 -point rating scale $(5=$ high concern, $4=$ middle concern, $3=$ concern, $2=$ little concern, 1 = no concern). In addition, we analyzed student's preferences at each of the three levels of "respect for food (respect)" and "concern about food (concern)". We grouped scores of the "concern" and "respect" variable into three categories: the 'high' included the responses 'higher', 'middle' included the responses 'high' whereas 'low' includes the responses 'medium', 'low', and 'none' according to the result of Table 2 and our previous study (Osera, Tsutie, Kobayashi \& Kurihara, 2016).

In addition, questions about SRH measures were included with five response categories (Joffer, Jerden, Ohman \& Flacking, 2016; Warnoff et al., 2016). In this study, we grouped scores of the SRH variable into two categories: the 'excellent' included the responses 'excellent' whereas 'other' includes the responses 'very good', 'good', 'fair' and 'poor' in Table 3.

Student's likes and dislikes were included in the questionnaire with the response to each being either "yes" or "no." If students answered "yes", students also chose the foods they disliked by themselves from a list of the following 55 foods: noodles, rice, bread, konjac, sweet potatoes, potatoes, azuki beans, soybeans, freeze-dried tofu, tofu, deep-fried tofu, sesame, pumpkin, peas, string beans, carrots, leeks, green peppers, broccoli, spinach, Japanese mustard spinach, cabbage, cucumber, burdock, Japanese radish, onions, corn, eggplant, Chinese cabbage, tomatoes, cherry tomatoes, bananas, tangerines, apples, pineapple, Enoki mushrooms, Shimeji mushrooms, dried shitake, toasted laver, Hijiki, seaweed, squid, shrimp, fish paste cake, Spanish mackerel, salmon, liver, beef, chicken, pork, cheese, yogurt, milk, eggs, and quail eggs. The foods on the list were selected from what is available at regular school lunches and often disliked by children as noted in our previous study (Osera, Tsutie, Kobayashi \& Kurihara, 2016). 


\subsection{Statistical Analysis}

We compared the student's food behaviors, including preferences, likes and dislikes, based on the three levels of respect and concern. In addition, we noted the top 10 disliked foods listed by the guardians or themselves. We compared the ratio of children who disliked each of the top 10 foods by the three levels of "respect" and "concern." The Kruskal-Wallis, Mann-Whitney U, and Jonckheer-Terpstra tests were used to compare the results using SPSS version 25.0 J (IBM, New York, NY, USA).

\subsection{Ethics Statement}

The students and their guardians were fully informed about the objectives and methods of this study. They voluntarily answered the questionnaire without any compulsion and with the understanding that they could withdraw from the study at any time. Individual privacy was strictly protected throughout the investigation. Signed consent was obtained from the guardians of each child. This study was approved by the Kobe Women's University Ethics Committee regarding Human Subjects (approval number H29-1).

\section{Results}

\subsection{Characteristics of the Answers for the Questions related to Food Habits}

Responses for questionnaire items related to food habits and lifestyle are shown in Tables 1 to 3. A total of 497 questionnaires were analyzed, which included 233 children of 6-12 years of age and 153 children of 13-16 years of age. There was no significant relationship among age, sex, and BMI (Table 1). Table 2 showed that there was a significant relationship between food preferences and "concern" or "respect."

Table 1. Baseline characteristics classified by food preferences

\begin{tabular}{lllllll}
\hline & Food preferences & \multicolumn{2}{l}{ Presence } & \multicolumn{2}{l}{ Absence } & P value $^{*}$ \\
\hline Items & Category & $\mathrm{N}$ & $\%$ & $\mathrm{~N}$ & $\%$ & \\
\hline Age & $6-12$ & 233 & $(58.0)$ & 58 & $(58.0)$ & N.S. \\
(y.o.) & $13-16$ & 153 & $(39.6)$ & 42 & $(42.0)$ & \\
Sex & Boy & 166 & $(43.1)$ & 54 & $(54.5)$ & N.S. \\
& Girl & 219 & $(56.9)$ & 45 & $(45.5)$ & \\
BMI & $<18.5$ & 290 & $(76.3)$ & 66 & $(67.3)$ & \\
$\left(\mathrm{kg} / \mathrm{m}^{2}\right)$ & $18.5-24.9$ & 85 & $(22.4)$ & 32 & $(32.7)$ & N.S. \\
& $>=25.0$ & 5 & $(1.3)$ & 0 & $(0.0)$ & \\
\hline
\end{tabular}

* Fisher's exact test.

Table 2. Association between food preferences and "Concern about food"/ "Respect for food"

\begin{tabular}{|c|c|c|c|c|c|c|}
\hline \multicolumn{2}{|l|}{ Food preferences } & \multicolumn{2}{|c|}{ Presence } & \multicolumn{2}{|c|}{ Absence } & \multirow[t]{2}{*}{ P value ${ }^{*}$} \\
\hline Items & Category & $\mathrm{N}$ & $\%$ & $\mathrm{~N}$ & $\%$ & \\
\hline \multirow{5}{*}{ Concern about food } & None & 16 & (4.1) & 0 & 0.0 & 0.000 \\
\hline & Low & 37 & (9.6) & 2 & 2.0 & \\
\hline & Medium & 73 & (18.9) & 9 & 9.0 & \\
\hline & High & 150 & (38.9) & 39 & 39.0 & \\
\hline & Higher & 110 & $(28.5)$ & 50 & 50.0 & \\
\hline \multirow[t]{5}{*}{ Respect for food } & None & 2 & $(0.5)$ & 0 & 0.0 & 0.000 \\
\hline & Low & 17 & (4.4) & 2 & 2.0 & \\
\hline & Medium & 43 & (11.2) & 4 & 4.0 & \\
\hline & High & 155 & (40.4) & 23 & 23.0 & \\
\hline & Higher & 167 & (43.5) & 71 & 71.0 & \\
\hline
\end{tabular}

* Fisher's exact test.

\subsection{Disliked Foods Stratified by "Concern about Food" and "Respect for Food" Levels}

Of all the children, $79.4 \%$ had some food disliked. The average number of disliked foods, of the 55 items listed, was $5.3 \pm 5.0$. The quartiles are shown in Table 3 .

Children in the low "Concern" level group had significantly more disliked foods compared with the middle and high "Concern" level groups $(6.0 \pm 5.2,5.1 \pm 5.6$, and $4.6 \pm 3.8$ items, respectively, $\mathrm{p}<0.05)$. Children in the low "Respect" level group had significantly more disliked foods compared with the middle and high groups as 
noted in Tables 4 and $5(7.0 \pm 6.7,4.9 \pm 4.4$, and $4.9 \pm 4.7$ items respectively, $\mathrm{p}<0.05)$. The number of foods that children disliked decreased significantly as the level of "Concern about food" and/or "Respect for food" increased.

Children chose the foods their children disliked from a list of 55 foods. The ratio of children who disliked each of the top 10 foods was investigated. Figure 1 showed that when children who disliked each of some of the top 10 disliked foods significantly or tendency reduced. This was similar to the number of foods children disliked relative to "Respect" and "Concern" shown below in Tables 4 and 5.

Table 3. Number of disliked food

\begin{tabular}{lrl}
\hline Count & N & $\%$ \\
\hline 1 to 2 & 116 & $(32.8)$ \\
3 to 4 & 93 & $(26.3)$ \\
5 to 7 & 68 & $(19.2)$ \\
8 to 42 & 77 & $(21.8)$ \\
\hline
\end{tabular}

Table 4. Average number of disliked foods among three levels of "Concern about food"

* $\mathrm{p}<0.05$ by Kruskal-Wallis test.

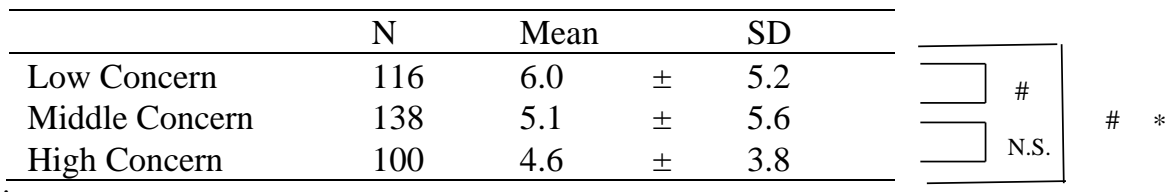

\# $\mathrm{p}<0.05$ by Mann-Whitney $U$ test.

SD: standard deviation N.S.: not significant

Table 5. Average number of disliked foods among three levels of "Respect for food"

* $\mathrm{p}<0.05$ by Kruskal-Wallis test.

\begin{tabular}{|c|c|c|c|c|c|}
\hline & $\mathrm{N}$ & Mean & & SD & \multirow[b]{4}{*}{ N.S. } \\
\hline Low Respect & 62 & 7.0 & \pm & 6.7 & \\
\hline Middle Respect & 149 & 4.9 & \pm & 4.4 & \\
\hline High Respect & 142 & 4.9 & \pm & 4.7 & \\
\hline
\end{tabular}

\# p<0.05, \#\# p<0.01 by Mann-Whitney U test.

SD: standard deviation N.S.: not significant

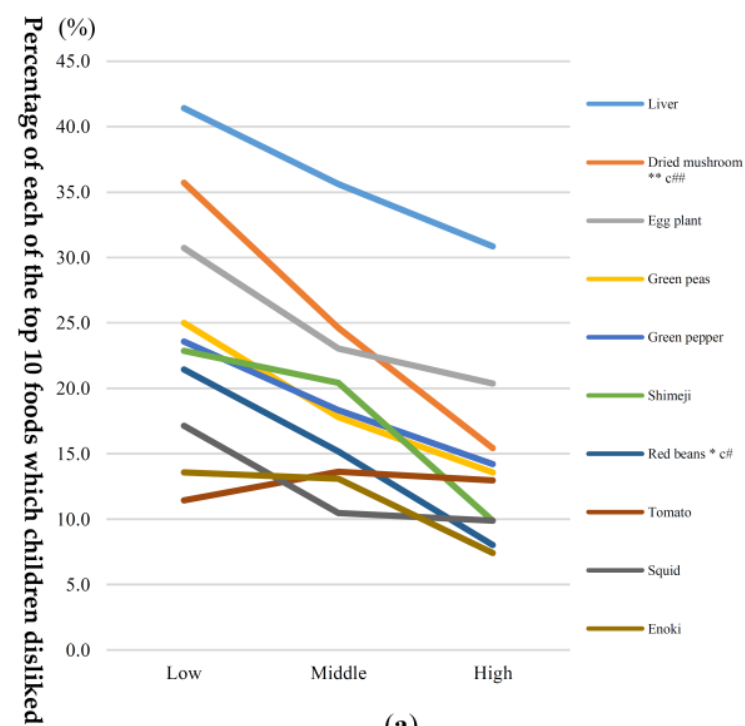

(a)

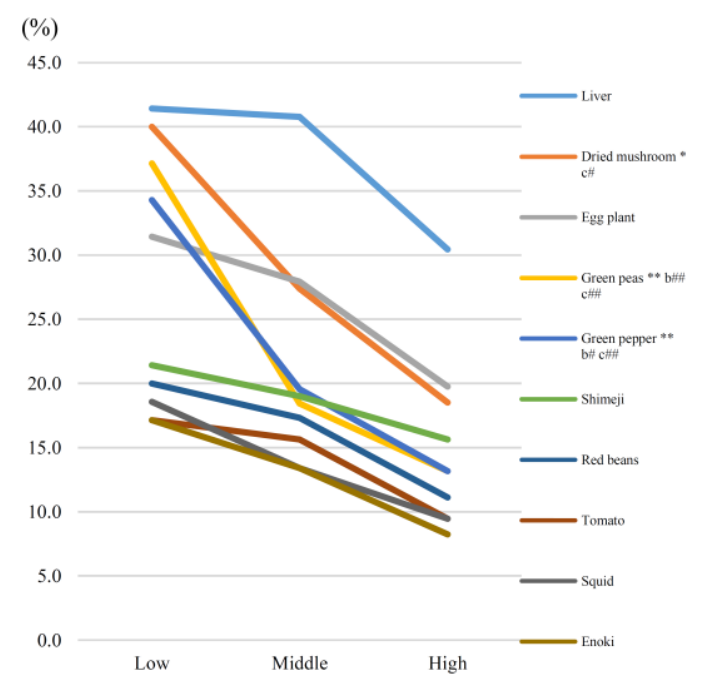

(b)

Figure 1. Percentage of children who disliked each of the top 10 disliked foods in the high, middle, and low groups stratified by (a) concern about food and (b) respect for food 
$* \mathrm{p}<0.05, * * \mathrm{p}<0.01$ by Jonckheere-Terpstra test; \# $\mathrm{p}<0.05$, \#\# $\mathrm{p}<0.01$ by Mann-Whitney $U$ test; a, High vs. Middle; b, Middle vs. Low; c, High vs. Low.

\subsection{Relationship between Presence or Absence of Food Preferences and Attitudes toward Food based on high to low "Concern about food" and "Respect for food"}

As shown in Table 2, we classified concern and respect into the following five levels: none, low, medium, high, and higher. The individual questions from the low and middle groups were subsequently stratified by "other" and "higher." We combined three groups to determine the relationship between the presence or absence of food preferences and concern/respect for food (data not shown). There was a significant relationship between food preferences and "Concern"/ "Respect" $(\mathrm{p}<0.001)$.

There was a significant relationship between food preferences and children's attitudes toward food without "help set the table" in "Concern." In the low and high groups, there was no significant relationship between food preferences and attitude toward food. In the middle group, there was no significant relationship between food preferences and attitude toward food except for talk about taste noted in Table 6 and Appendix Table A1.

In "Respect for food," there was a significant relationship between food preferences and attitude toward food except for "talk about food" and "help set the table." In the high and middle groups, there was no significant relationship between food preferences and attitude toward food. In the high group, there was a significant relationship between food preferences and attitude toward food except for "SRH," "talk about food," and "help set the table." In "respect for food," there was a significant relationship with "liking school lunch" and food preferences noted in Table 6.

Table 6. Association between food preferences and food habits based on high to low "Respect for food"

\begin{tabular}{|c|c|c|c|c|c|c|c|c|c|c|c|}
\hline \multirow{2}{*}{\multicolumn{2}{|c|}{\begin{tabular}{|l|} 
Respect for food \\
Food preferences \\
\end{tabular}}} & \multicolumn{5}{|c|}{ Low } & \multicolumn{5}{|c|}{ Middle } \\
\hline & & \multicolumn{2}{|c|}{ Presence } & \multicolumn{2}{|c|}{ Absence } & \multirow[t]{2}{*}{ Pvalue $^{*}$} & \multicolumn{2}{|c|}{ Presence } & \multicolumn{2}{|c|}{ Absence } & \multirow[t]{2}{*}{ P value } \\
\hline Items & Category & $\mathrm{N}$ & $\%$ & $\mathrm{~N}$ & $\%$ & & $\mathrm{~N}$ & $\%$ & $\mathrm{~N}$ & $\%$ & \\
\hline \multirow[t]{2}{*}{ SRH } & Other & 7 & 29.2 & 0 & 0 & N.S. & 13 & 36.1 & 1 & 8.3 & N.S. \\
\hline & $\begin{array}{l}\text { Very } \\
\text { good }\end{array}$ & 17 & 70.8 & 2 & 100 & & 23 & 63.9 & 11 & 91.7 & \\
\hline Talk about & Other & 54 & 87.1 & 6 & 100 & N.S. & 131 & 85.6 & 19 & 82.6 & N.S. \\
\hline food & Higher & 8 & 12.9 & 0 & 0 & & 22 & 14.4 & 4 & 17.4 & \\
\hline Talk about & Other & 50 & 80.6 & 5 & 83.3 & N.S. & 122 & 78.7 & 17 & 73.9 & N.S. \\
\hline taste & Higher & 12 & 19.4 & 1 & 16.7 & & 33 & 21.3 & 6 & 26.1 & \\
\hline Help set the & Other & 39 & 88.6 & 4 & 80 & N.S. & 81 & 81 & 13 & 86.7 & N.S. \\
\hline table & Higher & 5 & 11.4 & 1 & 20 & & 19 & 19 & 2 & 13.2 & \\
\hline Help & Other & 42 & 95.5 & 5 & 100 & N.S. & 92 & 92 & 14 & 93.3 & N.S. \\
\hline Cooking & Higher & 2 & 4.5 & 0 & 0 & & 8 & 8 & 1 & 6.7 & \\
\hline Liking & Other & 28 & 65.1 & 2 & 40 & N.S. & 62 & 62 & 9 & 60 & N.S. \\
\hline School & Higher & 15 & 34.9 & 3 & 60 & & 38 & 38 & 6 & 40 & \\
\hline \multicolumn{12}{|l|}{ Lunch } \\
\hline Liking & Other & 40 & 64.5 & 4 & 66.7 & N.S. & 63 & 40.9 & 11 & 47.8 & N.S. \\
\hline $\begin{array}{l}\text { Home } \\
\text { meals }\end{array}$ & Higher & 22 & 35.5 & 2 & 33.3 & & 91 & 59.1 & 12 & 52.2 & \\
\hline
\end{tabular}

*Fisher's exact test. 


\begin{tabular}{|c|c|c|c|c|c|c|c|}
\hline \multirow{3}{*}{$\begin{array}{l}\text { Respect for food } \\
\text { Food preferences } \\
\text { Items }\end{array}$} & \multirow[b]{3}{*}{ Category } & \multicolumn{6}{|c|}{ High } \\
\hline & & \multicolumn{2}{|c|}{ Presence } & \multicolumn{2}{|c|}{ Absence } & \multirow[t]{2}{*}{ P value ${ }^{*}$} & \multirow[t]{2}{*}{ P value* } \\
\hline & & $\mathrm{N}$ & $\%$ & $\mathrm{~N}$ & $\%$ & & \\
\hline \multirow[t]{2}{*}{ SRH } & Other & 9 & 27.3 & 2 & 14.3 & N.S. & 0.048 \\
\hline & Very good & 24 & 72.7 & 12 & 85.7 & & \\
\hline \multirow[t]{2}{*}{ Talk about food } & Other & 121 & 72.5 & 44 & 62 & N.S. & N.S. \\
\hline & Higher & 46 & 27.5 & 27 & 38 & & \\
\hline \multirow[t]{2}{*}{ Talk about taste } & Other & 106 & 63.9 & 34 & 47.9 & 0.03 & 0.002 \\
\hline & Higher & 60 & 36.1 & 37 & 52.1 & & \\
\hline \multirow[t]{2}{*}{ Help set the table } & Other & 61 & 69.3 & 24 & 63.2 & N.S. & N.S. \\
\hline & Higher & 27 & 30.7 & 14 & 36.8 & & \\
\hline \multirow[t]{2}{*}{ Help Cooking } & Other & 80 & 90.9 & 29 & 76.3 & 0.044 & 0.044 \\
\hline & Higher & 8 & 9.1 & 9 & 23.7 & & \\
\hline \multirow[t]{2}{*}{ Liking School Lunch } & Other & 46 & 52.3 & 8 & 21.1 & 0.002 & 0.000 \\
\hline & Higher & 42 & 47.7 & 30 & 78.9 & & \\
\hline \multirow[t]{2}{*}{ Liking Home meals } & Other & 50 & 29.9 & 11 & 15.5 & 0.023 & 0.011 \\
\hline & Higher & 117 & 70.1 & 60 & 84.5 & & \\
\hline
\end{tabular}

\section{Discussion}

In this study, we found that Japanese elementary and junior high school students' food preferences were associated with their "Attitude towards food." This is evidence for continuing to teach "Concern about food" and "Respect for food" during childhood and school age (Osera, Tsutie, Kobayashi \& Kurihara, 2016).

Picky children displayed more problem behaviors, both internalizing and externalizing, than non-picky eaters (Jacobi, Schmitz \& Agras, 2008). On the other hand, early childhood eating problems were not associated with later eating problems at 16 years of age (Hafstad, Soest \& Torgersen, 2013). Dovey et al. found that food neophobia peaked at the ages of 2 to 6 years (Dovey, Staples, Gibson \& Halford, 2008). A previous study of ours found that neophobia disappeared in $10 \%$ of children aged 4 to 6 years (Osera, Tsutie, Kobayashi \& Kurihara, 2014). Additionally, another previous study of ours suggested that although children may dislike some types of food, these dislikes may disappear as they become adolescents (Osera et al., $2017 \mathrm{~b}$ ). In addition, our previous study had a cross-sectional design, so we could not establish a clear causal relationship. However, the KAB model has shown that knowledge is a key factor in behavior (Ren et al., 2020).

The three levels of "concern about food" and "respect for food" are not significantly different among the levels as noted in Tables 6, and A-1. "Respect for food" was significantly related to "liking school lunch." The aim of Japanese public kindergarten guidelines is attention to "concern about food" (MEXT, 2018). As well, the aim of Japanese public primary school is attention to feelings for food (MEXT Course of home economics, 2018), which is similar to "respect for food" in this study. Additionally, our previous study suggested that changes in food preferences among 4 to 6-year-old children were related to their food habits. Enjoying school lunches and respect for food had a significant relationship with changes in food preferences among 4 to 6-year-olds within four groups (Osera, Tsutie, Kobayashi \& Kurihara, 2014). "Respect for food" in the high group had a significant relationship between food preferences and enjoying school lunch. This result supports the aim of the Japanese public primary schools of teaching attention to feelings for food (MEXT Course of home economics, 2018). In addition, Akamatsu \& Iuchi (2009) have performed research related to "Gratitude for food" . Their research revealed that children scoring higher in "Gratitude for food" ate vegetables every day compared with other children in grades 5 and 6 who hardly ate any vegetables. Based on these results, the presence or absence of food preference is likely to differ according to children's attitude toward food.

This study's top five disliked foods were liver, dried mushrooms, eggplant, green peas, and green peppers. These were the same as the most disliked foods as in our previous study (Osera, Tsutie, Kobayashi \& Kurihara, 2016). We found the same most disliked foods among high school students in this study as in our previous study (Osera et al., 2017). The same five foods were the most disliked in three different stages of life, but this is not representative of all Japanese, and we would like to repeat the study in different aged populations. In part, the results of this study may have been due to the presence of supertasters, those able to detect 6-n-propylthiouracil (PROP) (Fox, 1932; Cohen \& Ogdon, 1949; Harris \& Kalmus, 1949). Kosugi \& Horio (2005) found that $28 \%$ of the population were supertasters, and this taste sensitivity to PROP may be related to food preferences. As such, children's food preferences may be determined not only psychologically but also by physiology of taste. 
Rahill et al. (2018) found that age affects the level of food fussiness in children, with younger children (5-8 years old) having higher levels of food fussiness than older children (9-12 years old). This finding is similar to those observed in earlier studies (Powell, Farrow \& Meyer, 2011; Hursti \& Sjoden, 1997; Ashcroft et al., 2008). Older children are more likely to have had greater exposure to various foods, and they will become less neophobic as fewer foods are novel them (Cooke \& Wardle, 2005). In a future study, we will assess subjects of different ages. In a previous study, $74.6 \%$ of the mothers noted that their children disliked one or more foods (Osera, Tsutie, Kobayashi \& Kurihara, 2016). In this study, 79.4\% of the students answered that they disliked one or more foods. Additionally, the average number of disliked foods was the same as that of our previous study (Osera, Tsutie, Kobayashi \& Kurihara, 2016).

In addition "Respect for food" important for not only food preferences but also SDGs, there are connected with good health and well-being and quality education (United Nations, 2015). We think that the "Respect for food" is linked to sustainability.

Limitation of this study is that it cannot make clear the causal relationship. In the near future, we would test the hypotheses by interventional studies on the basis of the result of this study and our previous study (Osera, Tsutie, Kobayashi \& Kurihara, 2016) Based on behavior science, "attitude" is the leading factor of behavior. In addition, our previous children's retrospective cohort study suggested the same factors shown as this study's result; "Enjoying school lunch" and "Respect for food" (Osera, Tsutie, Kobayashi \& Kurihara, 2014). On the other hand, there study was small number and groups of different ages. It is necessary to continue the same survey in the future and confirm whether the same results can be obtained. Larger number of the study population with varied age distribution will be needed. However, it is an advance that similar trends in attitudes about food preferences were made clear in early childhood and elementary school and junior high school students. In addition, self-reported anthropometric measurements in young adults used to calculate BMI has its limitations. However, this will have potential impact on the results especially with the presence of the sample PROP. To future understand this phenomenon, we will do an interventional study on the basis of the result of this study in the near.

In this study, we found that student's food preferences were associated with their "Attitude towards food". These findings may provide important information for improving food preferences not only in young children but also in elementary school and junior high school students. In addition, this is the evidence for the importance of teaching "Respect for food" in schools.

\section{Acknowledgments}

We would like to thank all the children, guardians, and teachers for their contributions to this study.

\section{References}

Akamatsu, R., \& Izuchi, H. (2009). Reliability and validity of the "gratitude for food" scale for children. Journal of Japanese Society of Health Education and Health Promotion, 17(3), 147-159. https://doi.org/10.11260/kenkokyoiku.17.147

Ashcroft, J., Semmler, C., Carnell, S., Jaarsveld, CHM., \& Wardle, J. (2008). Continuity and stability of eating behavior traits in children. European Journal of Clinical Nutrition, 62, 985-990. https://doi.org/10.1038/sj.ejcn.1602855

Birch, L. L. (2013). The relationship between children's food preferences and those of their parents. Journal of Nutrition Education, 12(1), 14-18. https://doi.org/10.1016/S0022-3182(80)80249-4

Cano, S. C., Hoek, H. W., Hoeken, D., Barse, L. M., Jaddoe, V. W. V., Verhulst, F. C., \& Tiemeier, H. (2016). Behavioral outcomes of picky eating in childhood: a prospective study in the general population. Journal of Child Psychology and Psychiatry, 57(11), 1239-1246. https://doi.org/10.1111/jcpp.12530

Cohen, J., \& Ogdon, D. P. (1949). Taste blindness to phenylthiocarbamide and related compound. Psychological Bulletin Journal, 46, 490-498. https://doi.org/10.1037/h0060685

Cooke, L. J., \& Wardle, J. (2005). Age and gender differences in children's food preferences. British Journal of Nutrition, 93, 741-746. https://doi.org/10.1079/BJN20051389

Cosmi, V. D., Scaglioni S., \& Agostoni, C. (2017). Early taste experiences and later food choices. Nutrients, 9 , 107. https://doi.org/10.3390/nu9020107

Dovey, T. M., Staples, P. A., Gibson, E. L., \& Halford, J. C. G. (2008). Food neophobia and 'picky/fussy' eating 
in children: A review. Appetite, 50, 181-193. https://doi.org/10.1016/j.appet.2007.09.009

Dubois, L., Farmer, A. P., Girard, M., \& Peterson, K. (2007). Preschool children's eating behaviours are related to dietary adequacy and body weight. European Journal of Clinical Nutrition, 61, 846-855. https://doi.org/10.1038/sj.ejen.1602586

Dubois, L., Farmer, A., Girard, M., Peterson, K., \& Tatone-Tokuda, F. (2007). Problem eating behaviors related to social factors and body weight in preschool children: A longitudinal study. International Journal of Behavioral Nutrition and Physical Activity, 4, 9. https://doi.org/10.1186/1479-5868-4-9

Fox, A. L. (1932). The relationship between chemical constitution and taste. Genetics, 18(1), 115-120. https://doi.org/10.1073/pnas.18.1.115

Harris, H., \& Kalmus, H. (1949). The measurement of taste sensitivity to phenylthiourea (PTC). Annals of Eugenics, 15, 24-31. https://doi.org/10.1111/j.1469-1809.1949.tb02419.x

Hafstad, G. S., Soest, T., \& Torgersen, L. (2013). Early childhood precursors for eating problems in adolescence: a 15-year longitudinal community study. Journal of Eating Disorders, 1, 35. https://doi.org/10.1186/2050-2974-1-35

Hursti, U. K., \& Sjoden, P. (1997). Food and general nephobia and their relationship with self-reported food choice: familial resemblance in Swedish families with children of ages 7-17 years. Appetite, 29, 89-103. https://doi.org/10.1006/appe.1997.0108

Jacobi, C., Schmitz, G., \& Agras, W. S. (2008). Is picky eating an eating disorder? International Jouranl of Eating Disorders, 41(7), 626-634. https://doi.org/10.1002/eat.20545

Joffer, J., Jerden, L., \& Ohman, A. (2016). Flacking, R. Exploring self-rated health among adolescents: a think-aloud study. BMC Public Health, 16, 156. https://doi.org/10.1186/s12889-016-2837-z

Kazmarzyk, P. T., Janssen, I., Morrison, K. M., \& Tremblay, M. S. (2007). Classification of overweight and obesity in children and adolescents. Canadian Medical Association Journal, 176(8), 27-32.

Kosugi, R., \& Horio, T. (2005). Relationship between food preferences and taste sensitivity to PROP. The Japanese Journal of Nutrition and Dietetics, 63(5), 301-306. https://doi.org/10.5264/eiyogakuzashi.63.301

Mascola, A. J., Bryson, S. W., \& Agras, W. S. (2010). A. Picky eating during childhood: A longitudinal study to age 11 years. Eating Beahvior, 11, 253-257. https://doi.org/10.1016/j.eatbeh.2010.05.006

MEXT Courses of study for kindergarten. (2020). Retrieved from https://www.mext.go.jp/component/a_menu/education/micro_detail/_icsFiles/afieldfile/2018/04/25/13846 61_3_3.pdf

MEXT Courses of study of home economics for elementary school. (2020). Retrieved from https://www.mext.go.jp/a_menu/shotou/new-cs/1387014.htm

Miyazaki, S. (2018). Obesity diagnostic guidelines in 2016. The Journal of Japanese Society of Internal Medicine, 107, 262-268. https://doi.org/10.2169/naika.107.262

Osera, T., Tsutie, S., Kobayashi, M., \& Kurihara, N. (2012). Relationship of mothers' food preferences and attitudes with children's preferences. Food and Nutrition Sciences, 3, 1461-1466. https://doi.org/10.4236/fns.2012.310190

Osera, T., Tsutie, S., Kobayashi, M., \& Kurihara, N. (2014). A retrospective study on the relationship of changes in likes/dislikes with food habits in 4- and 6- year-old children. European Journal of Nutrition and Food Safety, 4(4), 604-613. https://doi.org/10.9734/EJNFS/2014/10604

Osera, T., Tsutie, S., Kobayashi, M., \& Kurihara, N. (2016). Associations between children's food preferences and food habits towards healthy eating in Japanese children. Journal of Child and Adolescent Behavior, 4(3), 1000292. https://doi.org/10.4172/2375-4494.1000292

Osera, T., Awai, M.., Kobayashi, M., Tsutie, S., \& Kurihara, N. (2017a). Relationship between self-rated health and lifestyle and food habits in Japanese high school students. Behavioral Sciences, 7, 71. https://doi.org/10.3390/bs7040071

Osera, T., Awai, M., Tsutie, S., Kobayashi, M., \& Kurihara, N. (2017b). A retrospective study on changes in food preferences of Japanese high school students from childhood to the present day. Journal of Food Research, 6(4), 150-158. https://doi.org/10.5539/jfr.v6n4p150

Osera, T., Taniguchi, N., Hashimoto, H., \& Kurihara, N. (2018). The effect on children's attitudes towards food 
associated with their non-cognitive skills, and with the nutrition knowledge of their parents. Journal of Educational and Developmental Psychology, 8(2), 1-8. https://doi.org/10.5539/jedp.v8n2p1

Pliner, P., \& Pelchat, M. L. (1986). Similarities in food preferences between children and their siblings and parents. Appetite, 7, 333-342. https://doi.org/10.1016/S0022-3182(80)80249-4

Powell, F. C., Farrow, C. V., \& Meyer, C. (2011). Food avoidance in children. The influence of maternal feeding practices and behaviors. Appetite, 57(3), 683-692. https://doi.org/10.1016/j.appet.2011.08.011

Rahill, S., Kennedy, A., Walton, J., McNulty, B. A., \& Kearney, J. (2018). The factors associated with food fussiness in Irish school-aged children. Public Health Nutrition, 22(1), 164-174. https://doi.org/10.1017/S1368980018002835

Ren, X., Geoffroy, E., Tian, K., Wang, L., Feng, L., Feng, J., ... Li, Z. (2020). Knowledge, attitudes, and behaviors (KAB) of influenza vaccination in China: A cross-sectional study 20 2017/2018. Vaccines, 8, 7. https://doi.org/10.3390/vaccines8010007

Scaglioni, S., Cosmi, V. D., Ciappolino, V., Parazzini, F., Brambilla, P., \& Agostoni, C. (2018). Factors influencing children's eating behaviours. Nutrients, 10, 706. https://doi.org/10.3390/nu10060706

Schwartz, C., Scholtens, P., Lalanne, A., Weenen, H., \& Nicklaus, S. (2011). Development of healthy eating habits early in life. Review of recent evidence and selected guidelines. Appetite, 57, 796-807. https://doi.org/10.1016/j.appet.2011.05.316

Sobek, G., Luszczki, E., Dabrowski, M., Deren, K., Baran, J., Weres, A., \& Mazur, A. (2020). Preferences for sweet and fatty taste in children and their mothers in association with weight status. International Journal of Environmental Research and Public Health, 17, 538. https://doi.org/10.3390/ijerph17020538

United Nations, Transforming our world: the 2030 Agenda for Sustinable Development. (2020). Retrieved from https://sustainabledevelopment.un.org/content/documents/21252030\%20Agenda\%20for\%20Sustainable\%2 0Development\%20web.pdf

Ventura, A. K., \& Worobey, J. (2013). Early influences on the development of food preferences. Current Biology, 23, R401-R408. https://doi.org/10.1016/j.cub.2013.02.037/nu9020107

Warnoff, C., Lekander, M., Hemmingsson, T., Sorgonen, K., Melin, B., \& Andreasson, A. (2016). Is poor self-rated heatlh associated with low-grade inflammation in 43110 late adolescent men of the general population? A cross-sectional study. BMJ open, 6, e009440. https://doi.org/10.1136/bmjopen-2015-009440

\section{Appendix A}

Table A-1. Association between food preferences and food habits based on high to low "Concern about food"

\begin{tabular}{lllllllllllll}
\hline Concern about food & \multicolumn{4}{l}{ Low } & \multicolumn{1}{l}{ Middle } \\
\hline Food preferences & & \multicolumn{1}{l}{ Presence } & \multicolumn{1}{l}{ Absence } & P value $^{*}$ & Presence & Absence & P value $^{*}$ \\
\hline Items & Category & $\mathrm{N}$ & $\%$ & $\mathrm{~N}$ & $\%$ & & $\mathrm{~N}$ & $\%$ & $\mathrm{~N}$ & $\%$ & \\
\hline SRH & Other & 14 & 36.8 & 0 & 0 & $\mathrm{~N} . \mathrm{S}$ & 10 & 29.4 & 2 & 22.2 & $\mathrm{~N} . \mathrm{S}$ \\
& Very good & 24 & 63.2 & 5 & 100 & & 24 & 70.6 & 7 & 77.8 & \\
Talk about food & Other & 113 & 90.4 & 11 & 100 & $\mathrm{~N} . \mathrm{S}$ & 128 & 85.3 & 29 & 74.4 & $\mathrm{~N} . \mathrm{S}$ \\
& Higher & 12 & 9.6 & 0 & 0 & & 22 & 14.7 & 10 & 25.6 & \\
Talk about taste & Other & 106 & 85.5 & 11 & 100 & $\mathrm{~N} . \mathrm{S}$ & 112 & 74.7 & 21 & 53.8 & 0.017 \\
& Higher & 18 & 14.5 & 0 & 0 & & 38 & 25.3 & 18 & 46.2 & \\
Help set the table & Other & 68 & 86.1 & 5 & 83.3 & N.S & 70 & 72.2 & 16 & 64 & N.S \\
& Higher & 11 & 13.9 & 1 & 16.5 & & 27 & 27.8 & 9 & 36 & \\
Help cooking & Other & 76 & 96.2 & 6 & 100 & N.S & 85 & 87.6 & 20 & 80 & N.S \\
& Higher & 3 & 3.8 & 0 & 0 & & 12 & 12.4 & 5 & 20 & \\
Liking school lunch & Other & 54 & 68.4 & 2 & 33.3 & N.S & 60 & 62.5 & 10 & 40 & N.S \\
& Higher & 25 & 31.6 & 4 & 66.7 & & 36 & 37.5 & 15 & 60 & \\
Liking home meals & Other & 60 & 47.6 & 4 & 36.4 & N.S & 67 & 45.0 & 15 & 38.5 & N.S \\
& Higher & 66 & 52.4 & 7 & 63.6 & & 82 & 55.0 & 24 & 61.5 & \\
\hline
\end{tabular}

* Fisher's exact test. 


\begin{tabular}{llllllll}
\hline Concern about food & \multicolumn{1}{l}{ High } & & & \\
\hline Food preferences & & Presence & Absence & P value $^{*}$ & P value $^{*}$ \\
\hline Items & Category & N & $\%$ & N & $\%$ & & \\
\hline SRH & Other & 5 & 22.7 & 1 & 7.1 & N.S & 0.048 \\
Talk about food & Very good & 17 & 77.3 & 13 & 92.9 & & \\
& Other & 67 & 61.5 & 29 & 58 & N.S & 0.021 \\
& Higher & 42 & 38.5 & 21 & 42 & & \\
Talk about taste & Other & 61 & 55.5 & 24 & 48 & N.S & 0.002 \\
& Higher & 49 & 44.5 & 26 & 52 & & \\
Help set the table & Other & 44 & 77.2 & 20 & 74.1 & N.S & \multirow{2}{*}{ N.S } \\
& Higher & 13 & 22.8 & 7 & 25.9 & & \\
Help cooking & Other & 54 & 94.7 & 22 & 81.5 & N.S & 0.043 \\
& Higher & 3 & 5.3 & 5 & 18.5 & & \\
Liking school lunch & Other & 23 & 40.4 & 7 & 25.9 & N.S & 0.000 \\
\multirow{4}{*}{ Liking home meals } & Higher & 34 & 59.6 & 20 & 74.1 & & \\
& Other & 27 & 24.5 & 7 & 14.0 & N.S & 0.011 \\
& Higher & 83 & 75.5 & 43 & 86.0 & & \\
\hline
\end{tabular}

\section{Copyrights}

Copyright for this article is retained by the author(s), with first publication rights granted to the journal.

This is an open-access article distributed under the terms and conditions of the Creative Commons Attribution license (http://creativecommons.org/licenses/by/3.0/). 